\title{
Did They Really Perform Crimes due to Dementia?
}

\author{
Nasim Zamani Farkhondeh Jamshidi \\ Department of Forensic Medicine and Toxicology, Tehran University of Medical Sciences, \\ Tehran, Iran
}

Dear Editor

I read with great interest the study performed by Kim et al. [1] entitled 'Criminal Manifestations of Dementia Patients: Report from the National Forensic Hospital' recently published in your journal. The authors have evaluated a total of 7 imprisoned dementia patients ( 2 probable Alzheimer's dementia patients, 1 vascular dementia patient, and 4 alcohol-related dementia patients) to evaluate clinical and criminal characteristics of dementia patients who had been incarcerated because of criminal activity. Although a very interesting idea, it seems that the authors have missed something very important about their patients. As they have themselves declared, 4 patients had been in a drunken state while performing criminal activities (one murder, two attempted murders, and two assaults). This is exactly in accordance with the invaluable comments of the authors of the book 'Knight's Forensic Pathology' that declares drunken persons are often involved in fatal traumas of any type. As they have described, a majority of the homicides are triggered by the aggressive behavior engendered by alcohol [2]. Maybe the fact that the 2 remaining patients in the present study who had not been drunken at the time of criminal activity (two larcenies) had performed less important crimes is in accordance with these statements as well. Maybe these 5 patients have performed these crimes because of being in a drunken state but not because of their dementia. Maybe a regression analysis while doing the statistical analysis could eliminate the effect of alcohol on these patients' criminal activities. Do the authors agree? Thank you for this very interesting study.

\section{References}

-1 Kim JM, Chu K, Jung KH, Lee ST, Choi SS, Lee SK: Criminal manifestations of dementia patients: report from the national forensic hospital. Dement Geriatr Cogn Dis Extra 2011;1:433-438.

2 Saukko P, Knight B: Forensic aspects of alcohol; in Saukk P, Knight B (eds): Knight's Forensic Pathology. London, Edward Arnold (Publishers), 2004, pp 552-559. 